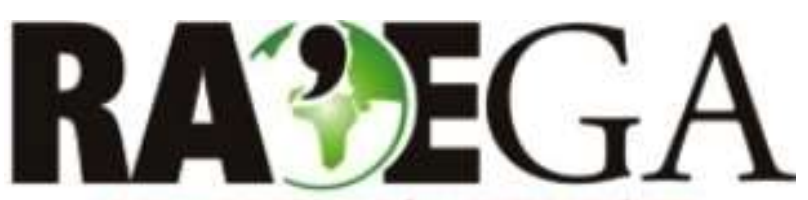

O ESPACO GEOGRÁFICO EM ANÁLISE

\title{
AVALIAÇÃO DO IMPACTO VISUAL DE PARQUES EÓLICOS NA QUALIDADE E ESTÉTICA DA PAISAGEM NO ENTORNO DE ÁREAS PROTEGIDAS: ESTUDO DE CASO DO PARQUE ESTADUAL DO GUARTELÁ, PR
}

\section{VISUAL IMPACT ASSESSMENT OF WIND FARMS IN QUALITY AND AESTHETICS OF LANDSCAPE SURROUNDING PROTECTED AREAS: A CASE STUDY OF GUARTELÁ STATE PARK, PR}

Cesar Augusto Crovador Siefert

Programa de Pós-graduação em Geografia Universidade Federal do Paraná - UFPR

Curitiba, PR, Brasil e-mail: cesarsiefert@ufpr.br

Irani dos Santos Departamento de Geografia Universidade Federal do Paraná - UFPR Curitiba, PR, Brasil e-mail: irani@ufpr.br

\section{Resumo}

A construção de parques eólicos tem sido adotada como uma alternativa para geração de energia renovável. Entretanto, um dos impactos mais evidenciados durante a sua implantação está relacionado a alterações na qualidade e estética da paisagem, sobretudo no entorno de áreas protegidas e com potencial turístico. Considerando duas alternativas locacionais para implantação do Complexo Eólico Campos Gerais (AL1 e AL2), na região de entorno do Parque Estadual do Guartelá, região dos Campos Gerais do estado Paraná, este artigo possui como objetivo avaliar possíveis impactos visuais na qualidade e estética da paisagem causados pela inserção dos aerogeradores na paisagem. Como método de análise, em conjunto com visitas a área de estudo, foram elaboradas simulações em ambiente tridimensional para avaliar as alterações provocadas na paisagem a partir dos locais de contemplação do canyon do rio lapó no parque. Foram delimitadas 4 zonas de impacto visual, de acordo com a distância e ângulo de visada entre os pontos de visada e os aerogeradores, contemplando graus de impactos nulo, baixo, médio e alto. Apesar da presença de 7 aerogeradores na AL2 inseridos em zona com grau de impacto visual Alto, o Complexo Eólico Campos Gerais não impactará de forma negativa na qualidade visual e estética da paisagem do canyon do rio 
lapó e do Parque Estadual do Guartelá. Esta constatação é devida as distâncias relativas entre o observador e os aerogeradores e aos ângulos de visada, confirmado pelas simulações 3D comparativas das AL1 e AL2.

Palavras-chave: impacto visual, parques eólicos, qualidade da paisagem, Parque Estadual do Guartelá.

\begin{abstract}
Wind farms construction has been adopted as an alternative for renewable energy generation. However, one of the most evidenced impacts during their construction is related with changes in landscape quality and aesthetics, mainly in protected areas with potential for tourism development. Considering two different proposals for Campos Gerais Wind Park implementation (LA1 and LA2), the main objective of this paper is evaluate potential visual impacts on landscape quality and aesthetics caused by the insertion of wind turbines surrounding Guartelá State Park. Fieldwork and three-dimensional simulations were designed to evaluate the changes in the landscape from viewpoints of the canyon lapó in the park. Four visual impact zones were defined according the distance between the viewpoints and wind turbines and the view angle, covering none, low, medium and high impacts. Despite the presence of seven wind turbines placed in areas with high visual impacts, no negative impacts were observed with the Campos Gerais Wind Complex LA2 in landscape's visual quality and aesthetic of the canyon lapó and Guartelá State Park. 3D simulations confirmed these results and it is due to distance between the observer to wind turbines and view angle from the viewpoints.
\end{abstract}

Keywords: visual impact, wind farms, landscape quality, Guartelá State Park.

\title{
1. INTRODUÇÃO
}

A construção de parques eólicos em diversos países tem sido adotada como uma alternativa para geração de energia renovável, transformando a energia oriunda dos ventos em eletricidade e reduzindo assim a dependência de outras formas de geração de energia como, por exemplo, usinas termelétricas, hidrelétricas ou nucleares.

Atualmente, citam-se como os impactos socioambientais mais graves durante a implantação de parques eólicos aqueles relacionados à qualidade $\mathrm{e}$ estética da paisagem, emissão de ruídos, alterações na dinâmica de aves e vida selvagem, formas de ocupação e manejo do território, sombreamento e interferência eletromagnética (KATSAPRAKAKIS, 2012). 
O impacto visual e estético relacionado a áreas públicas e turísticas é um dos principais fatores a serem levados em conta na implantação de um parque eólico (MOLNAROVA et al., 2012). Dentro deste contexto, Gipe (1995) afirma que a maior objeção para à construção de parques eólicos são os possíveis impactos causados pelas turbinas geradoras de energia nas funções estéticas da paisagem. E, paradoxalmente, embora estes empreendimentos denotem uma considerável preocupação ambiental, surge o questionamento sobre possíveis impactos em virtude do impacto visual causado pelas turbinas geradoras, sobretudo ao considerar a noção de qualidade da paisagem (LOTHIAN, 2008).

As qualidades visuais intrínsecas da paisagem, segundo Mopu (1987), residem na síntese entre os elementos naturais ou artificiais que a compõem. Assim, a paisagem como expressão visual do território e da interação espacial de todos os seus elementos pode assumir dimensões estéticas, culturais, geográficas e ecológicas e ser analisada tanto pelo seu caráter de síntese dos fatores de uma determinada porção do espaço, como pela sua condição de variável entre as demais no conjunto dos fatores ambientais. Neste sentido, a paisagem pode abarcar ainda uma qualidade estética, expressa em características físicas, culturais e sociais que denotam beleza cênica, como por exemplo, a região de implantação do Complexo Eólico Campos Gerais (CECG), com localização prevista para os arredores do Parque Estadual do Guartelá.

De maneira geral, dentro da noção de qualidade da paisagem, o termo qualidade tem sido empregado para abranger uma ampla gama de relações estabelecidas entre o ser humano e a paisagem em si, indo desde necessidades básicas, espirituais e valores naturalmente intrínsecos da própria paisagem. Assim, os canais de percepção humana atuam na construção da ideia de qualidade da paisagem e englobam conceitos como significado da paisagem e sentido de lugar, memórias, inferências e da construção de significados simbólicos, significações históricas / culturais / sociais, obrigações éticas / morais e valores espirituais (DANIEL, 2001). 
De acordo com Lothian (1999) existem dois paradigmas principais para avaliação da estética e qualidade da paisagem, sendo um moldado através de questões objetivas (Paradigma Físico - PF) e outro por análises subjetivas intrínsecas aos seres e comunidades envolvidos (Paradigma Psicossociológico - PS).

Estudos baseados no PF possuem prévias suposições (i.e. paisagens com beleza cênica definida) e avaliam a paisagem através de chaves de interpretação através de mapeamentos, simulações e classificações numéricas. Neste caso, assume-se que a qualidade da paisagem é um aspecto inerente a ela mesma, sendo assim uma característica física. Por outro lado, o PS considera a avaliação psicossociológica da comunidade envolvida como forma de analisar a qualidade da paisagem. Desta maneira, a qualidade e estética da paisagem estariam atreladas a capacidade de percepção do observador, sendo que esta capacidade é pessoal e torna-se variável de acordo com as características culturais, sociais e psicossociais do ser.

De maneira geral, com base nos pressupostos do PF, as noções de estética e qualidade da paisagem são geralmente associadas a qualidade visual e implicam em uma característica qualitativa inerente a própria paisagem, cujas propriedades visuais contém valores dignos de preservação e portanto, reconhecimento. Por sua vez, na abordagem do PS, esta paisagem visual não é dada puramente pelo aspecto visível. Pode-se fazer uma abordagem oposta aos pressupostos do PF ao considerar que, neste caso, a paisagem existe através de suas formas, sendo que somente o ser humano é que lhe dará um conteúdo (SANTOS, 1996).

O estabelecimento de um parque eólico envolve a construção das turbinas geradoras de energia além de uma infraestrutura necessária para 0 seu pleno funcionamento, como por exemplo, estradas de acesso, cabeamento subterrâneo para transmissão da energia gerada e uma subestação para regulação e transmissão da energia para a rede elétrica convencional.

Assim, o impacto visual de um parque eólico é baseado em sua influência na visualização da paisagem causada, sobretudo, pela instalação e 
operação dos aerogeradores. Esta alteração torna-se mais evidente em áreas que não possuem uma interferência humana consolidada, como por exemplo, em áreas rurais, protegidas ou costeiras. Em geral, no contexto científico notase um evidenciado interesse pela avaliação de impactos visuais em ambientes costeiros, sobretudo em países europeus (p.ex: BISHOP \& MILLER, 2007; LADENBURG \& DDUBGAARD, 2007; LADENBURG, 2009). No Brasil, destacam-se alguns estudos sobre a avaliação do impacto visual da implantação de parques eólicos que foram desenvolvidos no Rio Grande do Sul (p.ex.: VERDUM et al., 2012; DAITX, 2012), ambos conduzidos a partir de estudos de percepção da paisagem concebida por moradores das áreas impactadas.

A envergadura e o tamanho das torres combinado com a posição de instalação (usualmente no topo de colinas) fazem com que estas sejam visíveis mesmo em grandes distâncias (KATSAPRAKAKIS, 2012). Sendo assim, a percepção geral dos parques eólicos em áreas abertas varia de acordo com a distância do observador, ângulos de visada e as condições topográficas locais (Tabela 1).

Tabela 1: Percepções na paisagem em função da distância.

\begin{tabular}{ll}
\multicolumn{1}{c}{ Distância } & \multicolumn{1}{c}{ Percepção } \\
\hline até $2 \mathrm{~km}$ & Feição proeminente na paisagem. \\
$2-5$ & Feição relativamente proeminente na paisagem. \\
$5-15$ & Visto como parte da paisagem em um contexto geral. \\
$15-30 \mathrm{~km}$ & $\begin{array}{l}\text { Visto como um elemento secundário na paisagem (somente } \\
\text { visualizado em boas condições meteorológicas). }\end{array}$ \\
\hline
\end{tabular}

Fonte: University of Newcastle, 2002.

A distância entre o elemento e o observador influencia a capacidade de avaliação e percepção do impacto do parque eólico em um contexto regional (DE VRIES et al., 2012). E, de acordo com a distância ou mesmo o ângulo de visada em que a paisagem passível de alteração pela inserção de um novo 
elemento é visualizada, o resultado poderá ser inconclusivo uma vez que a avaliação poderá ser conduzida mediante interesses externos ao observador.

Entretanto, a influência visual da implantação de um parque eólico nas qualidades estéticas da paisagem é indubitável, porém possíveis impactos devem ser avaliados considerando parâmetros pré-estabelecidos de acordo com a paisagem e o contexto regional. Apesar dos valores de referência apresentados na Tabela 1, cita-se ainda que a real percepção visual do efeito das turbinas na paisagem é extremamente subjetiva (THAYER \& FREEMAN, 1987), fazendo com que a utilização de entrevistas como ferramentas de avaliação antes da implantação do parque torne-se tarefa extremamente complexa. Na tentativa de limitar este viés subjetivo na avaliação, alguns parâmetros objetivos que denotam a aceitação visual do parque eólico são utilizados em distintos estudos (Tabela 2).

Tabela 2: Parâmetros objetivos de avaliação do impacto de parques eólicos na paisagem.

\section{Parâmetro Justificativa}

A zona de impacto visual de um parque eólico instalado em uma área plana é menos ampla do que se instalado no topo de colinas. Por outro

Local de instalação lado, o impacto visual na paisagem pode ser considerado mais intenso em paisagens estreitas e fechadas (p.ex.: vales) se comparado com áreas abertas.

Empreendimento em operação

Beleza cênica

Particularidades em geral

Cor e modelo da turbina geradora
Quando o parque está em plena operação, a percepção pública é de que ele é útil, servindo ao seu propósito. Neste caso, torna-se visualmente aceitável na paisagem.

A instalação de um parque eólico em áreas de reconhecida beleza cênica pode causar reações negativas na comunidade envolvida.

A existência de destinos turísticos ou áreas arqueológicas no local de instalação poderá gerar empecilhos durante o procedimento de projeto de licenciamento e a instalação das turbinas.

A uniformidade do aerogerador é baseada na relação harmônica entre as dimensões principais das torres (altura, largura, envergadura das 


\begin{tabular}{ll}
\hline \multicolumn{1}{c}{ Parâmetro } & \multicolumn{1}{c}{ Justificativa } \\
\hline de energia & hélices, tamanho do rotor). Outro aspecto relevante é que conforme a \\
& $\begin{array}{l}\text { cor do conjunto instalado, a sua integração visual na paisagem pode ser } \\
\text { facilitada. }\end{array}$
\end{tabular}

Fonte: Katsaprakakis (2012).

Em levantamento realizado por Lothian (2008) sobre a aceitação da implantação de parques eólicos em locais diversos no Reino Unido, avaliada mediante entrevistas com a comunidade envolvida, constatou-se que a maioria das pesquisas com entrevistas realizadas após a sua construção, sejam realizadas com residentes ou turistas, chegam a conclusões similares. De maneira geral, nas consultas a população após a implantação dos parques eólicos, a grande maioria dos residentes mostrou-se favorável a construção do parque, observando de forma positiva o impacto das turbinas na paisagem, culminando com um possível apoio a novos projetos eólicos e ainda, em alguns casos, notando uma melhora na qualidade da paisagem, tornando-a mais interessante.

Entretanto, apesar dos resultados favoráveis citados por Lothian (2008), alguns autores são enfáticos ao afirmar que a implantação de parques eólicos em áreas de notável beleza cênica traz consigo uma queda perceptível na qualidade da paisagem destes locais ao longo do tempo (LOTHIAN, 2008; KATSAPRAKAKIS, 2012), demostrando a subjetividade deste tipo de avaliação.

Dentro desta perspectiva, o projeto do Complexo Eólico Campos Gerais prevê a implantação de um parque eólico com 250 aerogeradores e capacidade total de 968,3 MW localizado no entorno do Parque Estadual do Guartelá (PEG), 2ำ Planalto Paranaense na região dos Campos Gerais (municípios de Castro, Carambeí e Tibagi) no estado do Paraná. Cada aerogerador é composto por uma torre tubular adelgaçada com 98m de altura e um rotor de três pás de $52,5 \mathrm{~m}$ de comprimento (108m de diâmetro), que varrem uma área circular de 9.156,2m². 
Considera-se que a implantação do PEG teve como objetivo assegurar a preservação de ecossistemas típicos, locais de excepcional beleza cênica como o canyon do rio lapó e diversas cachoeiras, além de significativo patrimônio espeleológico, arqueológico e pré-histórico, em especial pinturas rupestres (PARANÁ, 1996). Neste sentido, ao buscar a preservação do parque devido a sua beleza cênica pode-se fazer uma ligeira aproximação entre a criação do PEG com a noção de preservação do patrimônio geomorfológico. Panizza \& Piacente $(1993,2003)$ definem patrimônio geomorfológico como sendo constituído pelas geoformas, incluindo também os processos morfogenéticos passados ou atuais, aos quais foram atribuídos valores científicos, culturais, estéticos e/ou econômicos. Desta maneira, considerando que um dos pressupostos para a implantação do PEG seja salvaguardar a beleza cênica do canyon do rio lapó, torna-se factível a avaliação do impacto visual da implantação do CECC na região de entorno do parque.

Por fim, este artigo possui como objetivo principal avaliar possíveis impactos visuais na qualidade e estética da paisagem considerando duas alternativas locacionais para implantação de um parque eólico nas adjacências do Parque Estadual do Guartelá e canyon do rio lapó. Considerando uma avaliação de impactos baseada nos pressupostos do paradigma físico, esta avaliação foi conduzida a partir de modelagens tridimensionais dos locais de visualização da paisagem do PEG e visitas orientadas a campo, de forma a excluir o viés subjetivo inerente às entrevistas com a comunidade envolvida.

\section{MATERIAIS E MÉTODOS}

O Parque Estadual do Guartelá foi criado através do Decreto Estadual noำ 2.329 de 24 de setembro de 1996 que regulamentou a sua criação, sendo oficialmente implantado em 1997. Sua implantação está embasada na Lei $n^{\circ}$ 4.771 de 15 de setembro de 1965 (institui o Código Florestal), Decreto no 84.017 de 21 de setembro de 1979 (que regulamenta os Parques Nacionais) e na Lei no 9.985, de 18 de julho de 2000 (que institui o Sistema Nacional de Unidades de Conservação - SNUC). 
O PEG está inserido na Área de Proteção Ambiental (APA) da Escarpa Devoniana, município de Tibagi, a aproximadamente $200 \mathrm{~km}$ de Curitiba, na região dos Campos Gerais do estado do Paraná (Figura 1). O canyon do rio lapó, afluente da margem direita do rio Tibagi, possui $32 \mathrm{~km}$ de extensão na direção NW-SE, com desnível aproximado de 450 metros. Este aprofundamento do leito do rio lapó deve-se a resistência diferenciada entre as rochas de seu leito (SOARES, 1997; HORNES, 2011).

A região do PEG está inserida no Segundo Planalto Paranaense, com relevo suavemente ondulado, no reverso do escapamento Furnas que por sua vez é caracterizado por relevo de cuesta formado por erosão diferencial, sendo constituído por sedimentos paleozóicos do devoniano, carbonífero e do permiano (RETZLAF et al., 2006).

O Parque foi instituído com o objetivo de assegurar a preservação de ecossistemas típicos, locais de excepcional beleza cênica como o canyon do rio lapó e diversas cachoeiras, além de significativo patrimônio espeleológico, arqueológico e pré-histórico, em especial pinturas rupestres, conforme descrito no Decreto Estadual oㅡ 2.329/96 (PARANÁ, 1996), que regulamenta a criação do parque.

A análise do impacto visual na paisagem das duas alternativas locacionais para implantação do CECG foi realizada dando maior ênfase nas áreas de conservação da natureza e reconhecida beleza cênica localizadas no entorno do Parque Estadual do Guartelá (PEG) (Figura 1).

Além do PEG, destacam-se ainda outras áreas particulares de preservação da natureza na região, como por exemplo, duas Reservas Particulares do Patrimônio Natural (RPPNs) - RPPN Fazenda Mocambo e RPPN Reserva Ecológica Ita-Y-Tiba, localizadas no lado oposto do canyon do rio lapó em relação ao sítio de implantação do CECG.

Com base no exposto, neste estudo utilizou-se métodos oriundos do paradigma físico para avaliação de impactos do empreendimento na qualidade da paisagem, considerando os possíveis efeitos da implantação do parque 
eólico na beleza cênica da paisagem na região de entorno do canyon do rio lapó, sobretudo no que tange ao Parque Estadual do Guartelá.

Desta maneira, a avaliação foi desenvolvida a partir da análise empírica de simulações computacionais do efeito da implantação do parque eólico na paisagem. Objetiva-se compreender os impactos visuais das turbinas nos pontos de visitação e contemplação do canyon do rio lapó, sobretudo nas trilhas de uso intensivo e nos mirantes do Parque Estadual do Guartelá. 


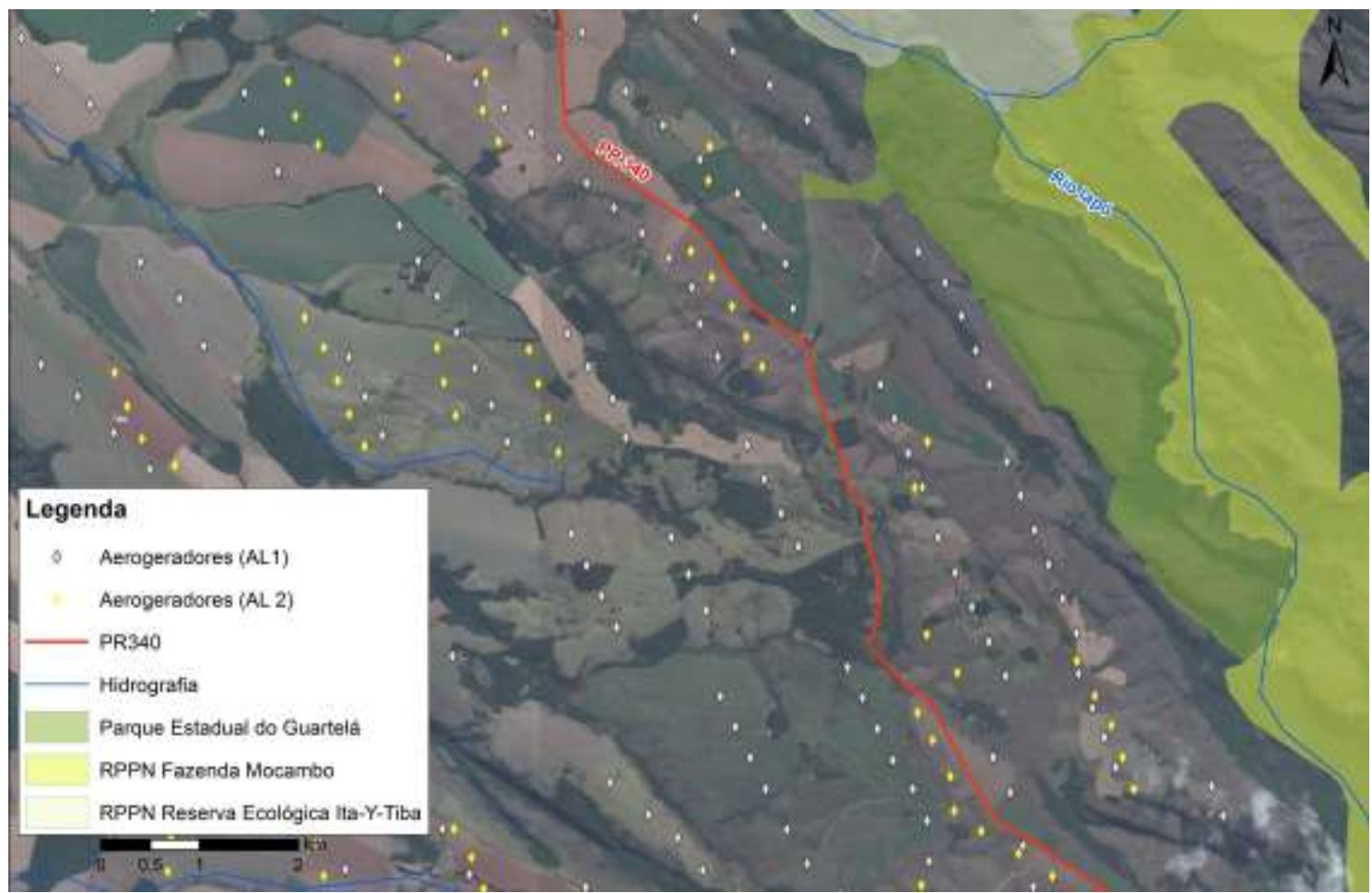

Figura 1: Localização do Parque Estadual do Guartelá em relação aos aerogeradores previstos nas duas alternativas locacionais (AL1 e AL2) para o Complexo Eólico Campos Gerais.

Neste sentido, buscou-se identificar as características que promovam a qualidade visual da paisagem em questão, especialmente considerando locais de visadas para as feições que contém beleza cênica, como alicerce para determinar como e de qual maneira o projeto de implantação do CECG irá afetar estes valores cênicos e estéticos da paisagem em seu entorno.

A avaliação do impacto visual da implantação do CECG foi realizada a partir da elaboração de simulações computacionais utilizando modelos tridimensionais das turbinas geradoras de energia, elaborados no software WindPRO e a inserção destes modelos no Google Earth, visando simular os efeitos dos aerogeradores para as duas alternativas locacionais em distintos pontos de visada do canyon do rio lapó. 
As simulações foram realizadas a partir de pontos previamente escolhidos pela relevância paisagística e demanda turística. Seguindo este critério foram escolhidos 5 pontos de controle (Tabela 3).

Tabela 3: Locais escolhidos para a simulação do impacto visual da implantação do Complexo Eólico Campos Gerais.

\begin{tabular}{|c|c|c|}
\hline Ponto & Coordenadas Geográficas & Localização \\
\hline PV1 & 2434'10.01"S; 50¹5'56.73"O & PEG - Recepção \\
\hline PV2 & 24³3'47.22"S; 50¹5'16.04"O & PEG - Trilha das Pinturas Rupestres \\
\hline PV3 & 24³3'51.66"S; 50¹5'2.90"O & PEG - Mirante Natural \\
\hline PV4 & 243'34.33"S; 50॰15'23.30"O & PEG - Mirante Principal \\
\hline PV5 & 2432'49.18"S; 50¹4'59.38"O & RPPN Ita-Y-Tyba \\
\hline
\end{tabular}

Para avaliação dos impactos na qualidade visual e estética da paisagem causado pelo CECG utilizou-se uma chave de interpretação baseada na distância relativa e ângulo de visada do observador em relação aos aerogeradores. Como forma ilustrativa, a Figura 2 apresenta a relação escalar entre um ponto de visualização dos aerogeradores, considerando a distância do observador e do parque eólico. Desta forma, observa-se que quanto maior a distância entre o observador e o aerogerador, a percepção visual do impacto na paisagem é suavizada, sendo paulatinamente absorvida pela paisagem e pouco alterando a sua estética (KATSAPRAKAKIS, 2012), embasando a metodologia utilizada para análise e descrição de impactos do empreendimento (HULL \& BISHOP, 1988; BISHOP, 2002). 


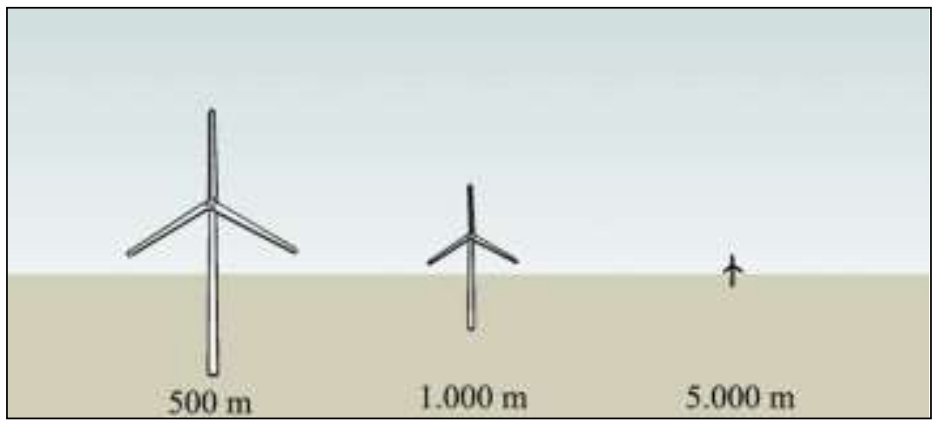

Figura 2: Grau de impacto visual de um aerogerador em função de distâncias aleatórias do observador em relação ao local de implantação, considerando um ângulo de visada ortogonal ao eixo dos aerogeradores. (KATSAPRAKAKIS, 2012).

Desta maneira, como forma de avaliação do grau de impacto visual na paisagem, utilizou-se como parâmetro de interpretação os valores de distância associados ao ângulo de visada entre o observador e os aerogeradores do CECG mostrados na Tabela 4, considerando as variáveis estabelecidas na Tabela 1.

Tabela 4: Chave de interpretação para avaliação do grau de impacto visual.

\begin{tabular}{lc}
\hline \multicolumn{1}{c}{ Distância } & Grau de impacto visual \\
\hline até $2 \mathrm{~km}$ & Alto \\
$2-5$ & Médio \\
$5-15$ & Baixo \\
$15-30 \mathrm{~km}$ & Nulo \\
\hline
\end{tabular}

\section{RESULTADOS E DISCUSSÃO}

A Figura 3 apresenta a localização dos pontos de visada (PV) do canyon do rio lapó em relação as duas alternativas locacionais do CECG. Cada ponto de visada (PV) é apresentado em conjunto com as suas respectivas áreas definidas como de alto grau de impacto visual (distância PV - aerogeradores < $2 \mathrm{~km}$ ). A direção das simulações apresentada nas figuras sequentes é indicada pelas setas pretas no entorno dos pontos de visada e as áreas de GIV foram 
delimitadas a partir de um buffer com distância de $2 \mathrm{~km}$ em $360^{\circ}$ a partir de cada PV.

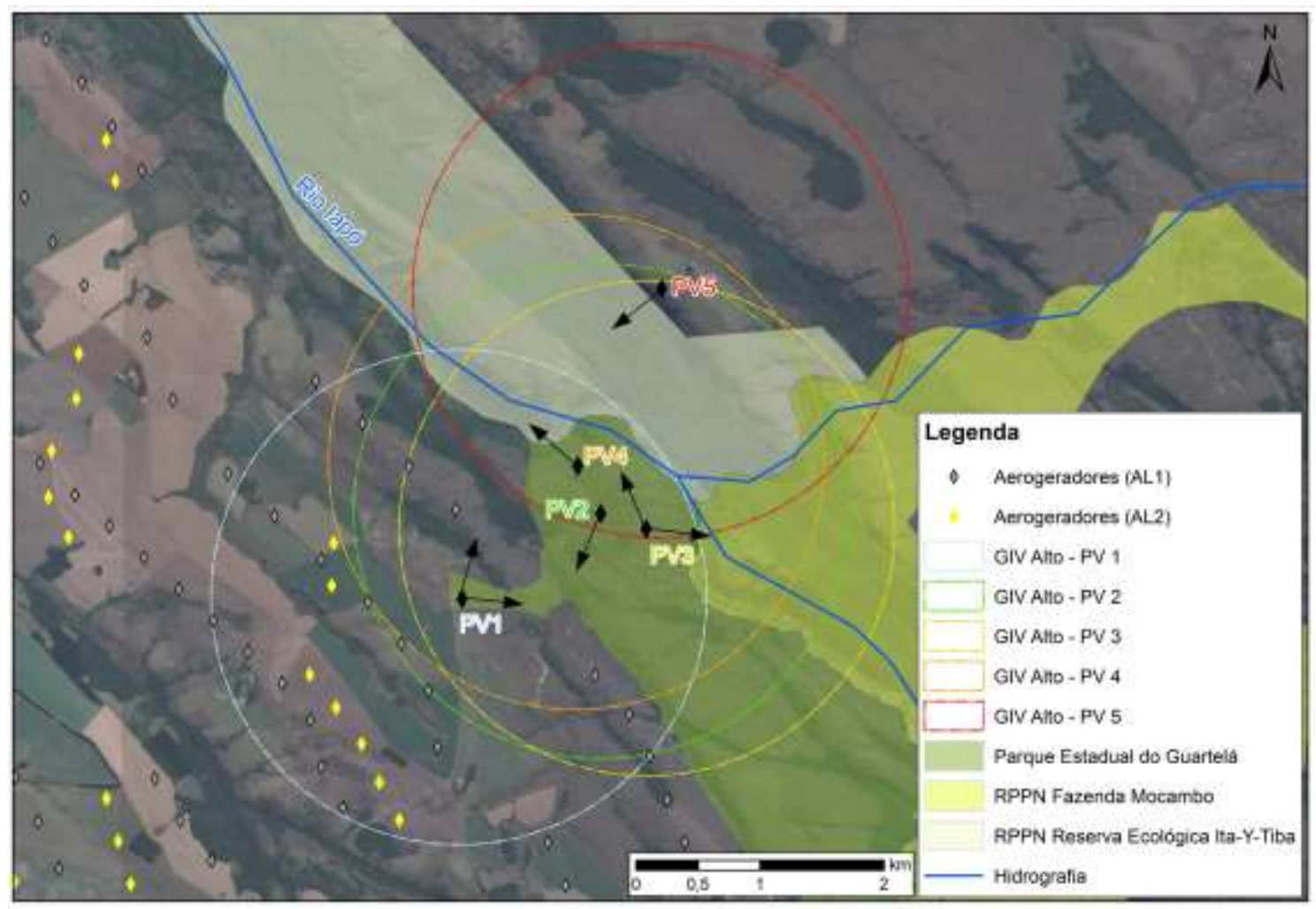

Figura 3: Localização dos pontos de visada do canyon do rio lapó no Parque Estadual do Guartelá (PEG) e na RPPN Ita-Y-tyba e respectivas áreas de alto Grau de Impacto Visual (GIV) delimitadas.

Desta forma, com as simulações realizadas, tornou-se possível a visualização do CECG nos pontos de controle localizados no entorno do canyon do rio lapó, a partir dos locais turísticos de contemplação da paisagem.

Ressalta-se ainda que um dos principais objetivos de criação do Parque Estadual do Guartelá é justamente a preservação da beleza cênica da paisagem esculpida pelo canyon do rio lapó, visando ainda salvaguardar suas geoformas e as potencialidades naturais da paisagem. Portanto, o impacto visual destes equipamentos pode ser minimizado pela posição relativa dos mesmos ao considerar os locais de maior visitação turística do parque. 
Considerando um panorama geral das alternativas locacionais do CECG, a Figura 4 apresenta a delimitação das áreas de abrangência dos diferentes graus de impacto visual, a saber: Alto, Médio, Baixo e Nulo, conforme apresentado na Tabela 4.

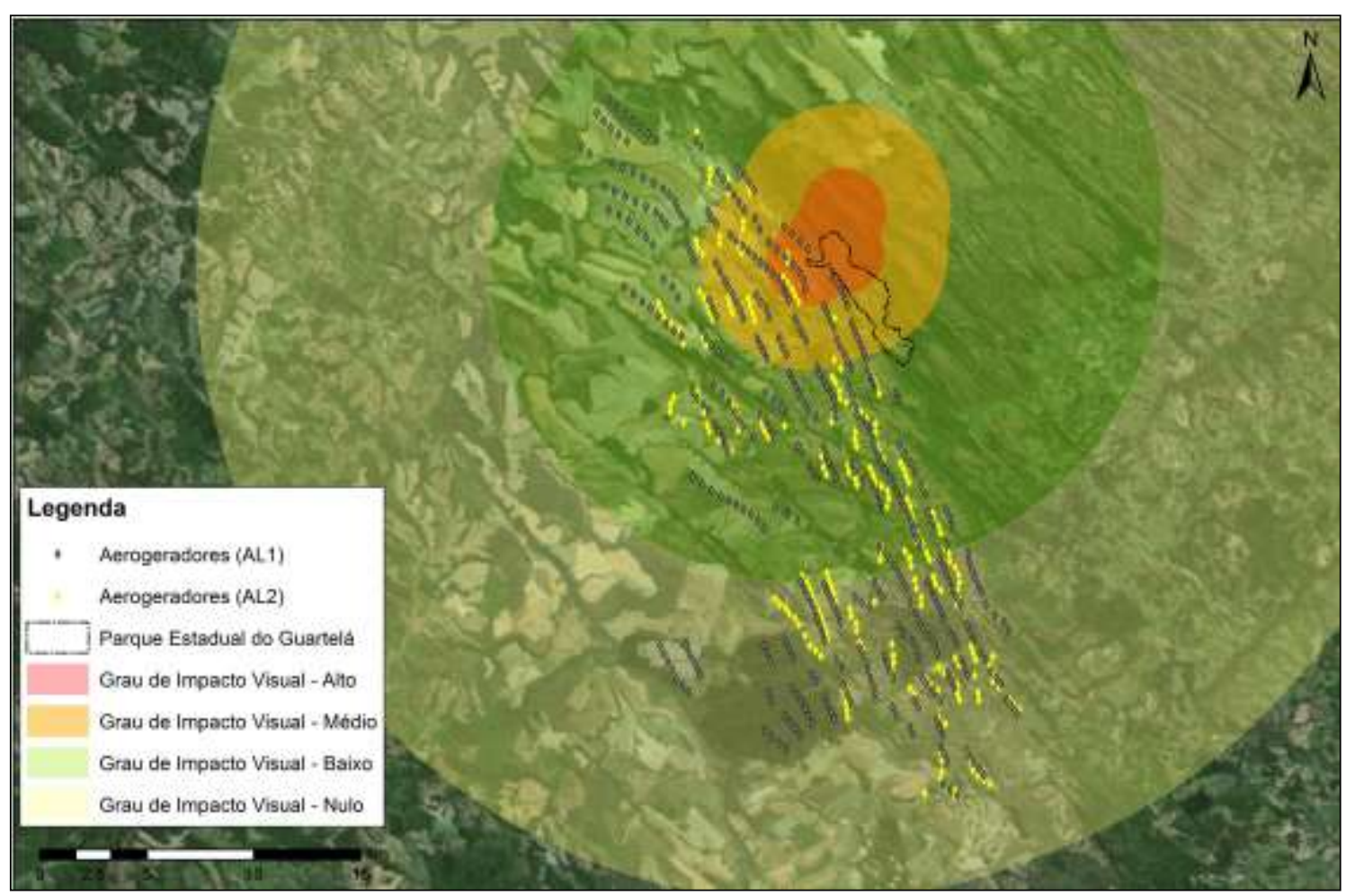

Figura 4: Graus de impacto visual da paisagem utilizadas como critério para avaliação dos impactos visuais do Complexo Eólico Campos Gerais na qualidade e estética da paisagem.

Nas Figuras 3 e 4, para as AL1 e AL2 observam-se, respectivamente, 18 e 7 aerogeradores localizados na área de alto grau de impacto visual considerando-se restritamente o critério de distância. Como forma de comparação dos impactos a qualidade visual e estética da paisagem associados as AL1 e AL2, as Figuras 5, 6, 7 e 8 apresentam o comparativo da situação real (Figura $X_{a}$ ), com as simulações das implantações do CECG AL1 (Figuras $X_{b}$ ) e CECG AL2 (Figura $X_{C}$ ).

Em relação a $A L 1$, nota-se a presença de 3 fileiras de aerogeradores mais próximas do canyon do rio lapó na zona de alto impacto visual dos PV1, 
PV2, PV3 e PV4 (Figura 3). Neste sentido, destaca-se ainda que, pelo critério da distância e ângulo de visada observa-se um alto impacto visual na paisagem a partir da consideração dos aerogeradores como feições proeminentes a relativamente proeminentes nestes locais, sobretudo considerando os PV1, PV3 e PV4 (Figuras $5 a_{2}$ e $5 b_{2}$ e $7 a_{2}$ e $7 b_{2}$ ).
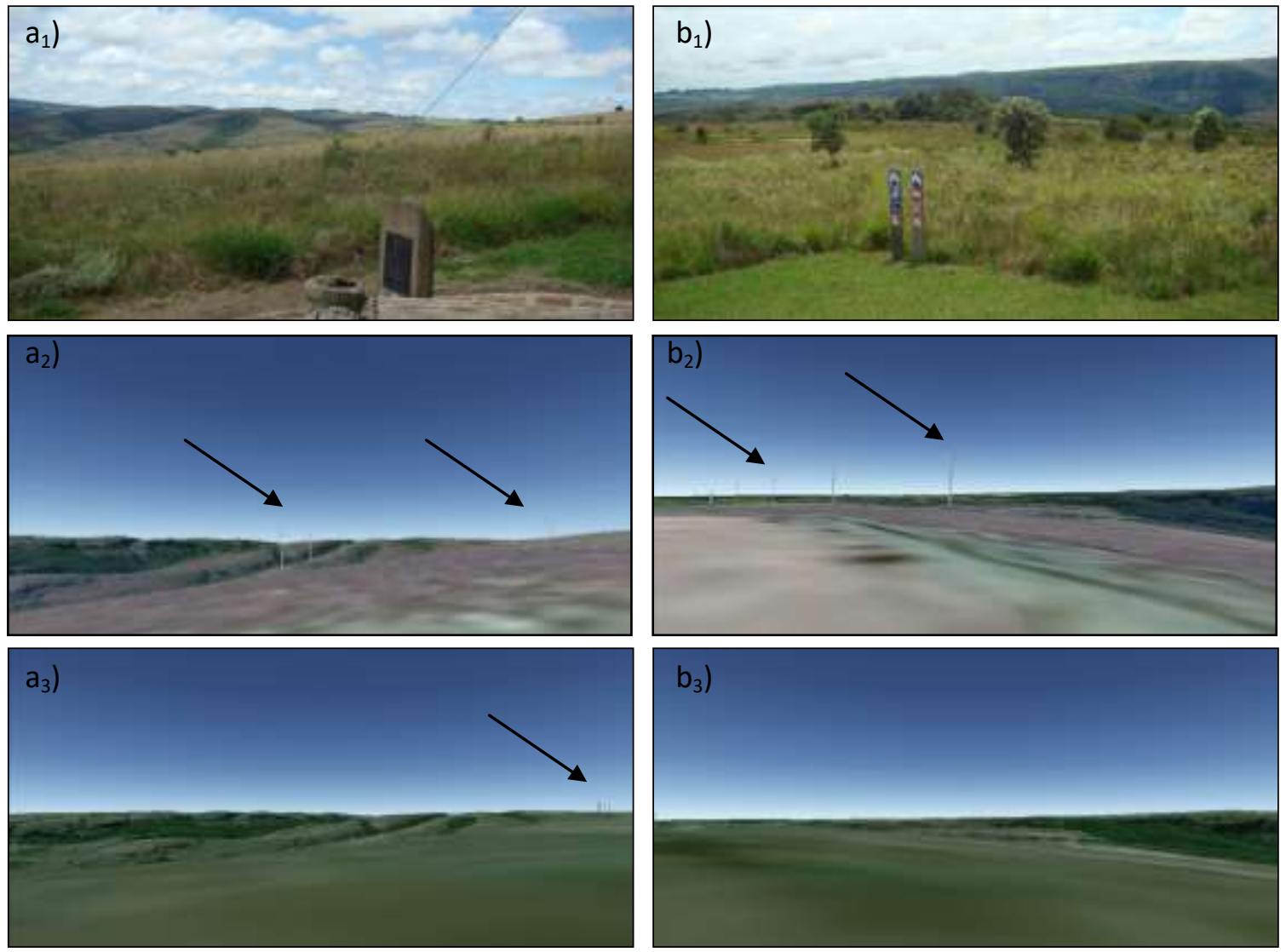

Figura 5: Comparativo da situação atual $\left(x_{1}\right)$ com simulação da implantação do Complexo Eólico Campos Gerais AL1 $\left(x_{2}\right)$ e AL2 $\left(x_{3}\right)$ a partir do (a) PV1 (sentido oeste) e (b) PV1 (sentido leste).

No entanto, na AL2, apesar destes pontos estarem enquadrados como alto impacto pela distância determinada a partir do PV1 e PV2, mostradas nas Figuras $5 a_{3}, 5 b_{3}$ e $6 a_{3}$, que estes sete aerogeradores aparecem como elementos secundários nas visadas consideradas quando comparados com a possível implantação da AL1. Neste sentido, destaca-se que a distância relativa 
entre o observador nos PVs aos aerogeradores é superior na AL1 quando comparado com AL2.

Em geral, para a AL2, é possível a visualização da linha de frente dos aerogeradores nos locais de visada PV1, PV2 e PV3 (sentido leste, oposto ao cạnyon do rio lapó) (Figuras $5 a_{3}, 5 b_{3}$ e $6_{1} a_{3}$ ), com distâncias entre o local de visada até a linha de frente de aerogeradores do Complexo Eólico variando entre $1,5 \mathrm{~km}$ a $4,5 \mathrm{~km}$. Nos locais de visada PV3 (sentido oeste ao canyon do rio lapó) e PV4 (vista para jusante do rio lapó) torna-se possível a visualização de diversos aerogeradores (Figura 6), entretanto, dada a distância entre o local de visada até o complexo $(5,4 \mathrm{~km}$ e $4,6 \mathrm{~km}$, respectivamente), estes já são incorporados como elementos secundários na paisagem.
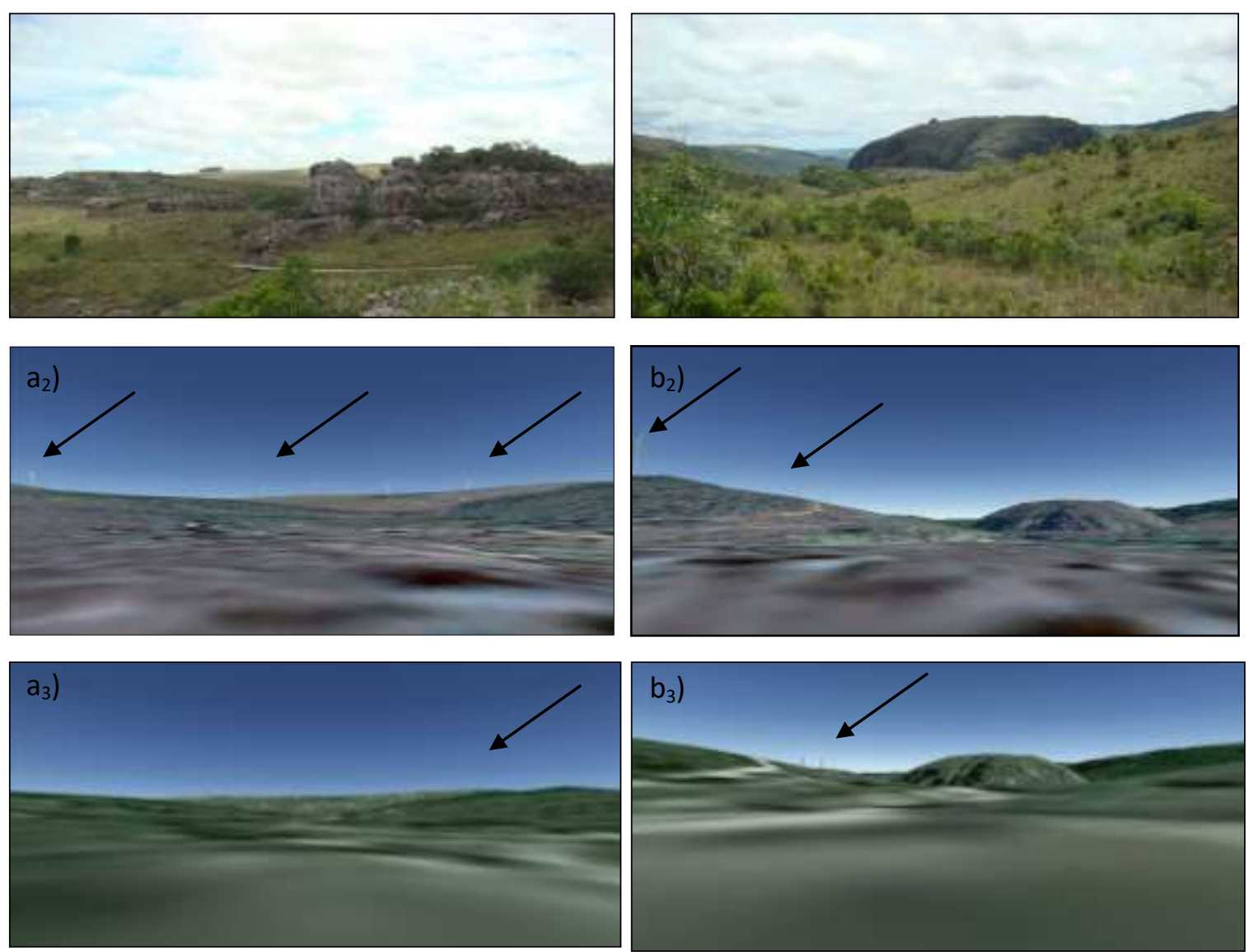

Figura 6: Comparativo da situação atual $\left(x_{1}\right)$ com simulação da implantação do Complexo Eólico Campos Gerais AL1 $\left(x_{2}\right)$ e AL2 $\left(x_{3}\right)$ a partir do (a) PV2 (vista oposta ao canyon do rio lapó) e (b) PV3 (vista sentido leste, oposta ao canyon do rio lapó). 
AVALIAÇÃO DO IMPACTO VISUAL DE PARQUES EÓLICOS NA QUALIDADE E ESTÉTICA DA PAISAGEM NO ENTORNO DE ÁREAS PROTEGIDAS: ESTUDO DE CASO DO PARQUE ESTADUAL DO GUARTELÁ, PR

Com relação aos mirantes PV3 - Natural e PV4 - Mirante Principal do $P E G$, têm-se que na AL1 os aerogeradores estão relativamente próximos do observador (aproximadamente 1,0 a 1,5 km ), de modo que sua visualização é plena considerando o sentido de visada do canyon do rio lapó (Figuras $7 \mathrm{a}_{2} \mathrm{e}$ $7 b_{2}$ ). Comparativamente, na AL2 os aerogeradores (Figuras $7 a_{3}$ e $7 b_{3}$ ) apresentam-se pouco visíveis na paisagem, sobretudo considerando o PV3. A Figura 8 apresenta ainda um comparativo entre as duas alternativas locacionais no sentido oposto ao Parque Estadual do Guartelá.
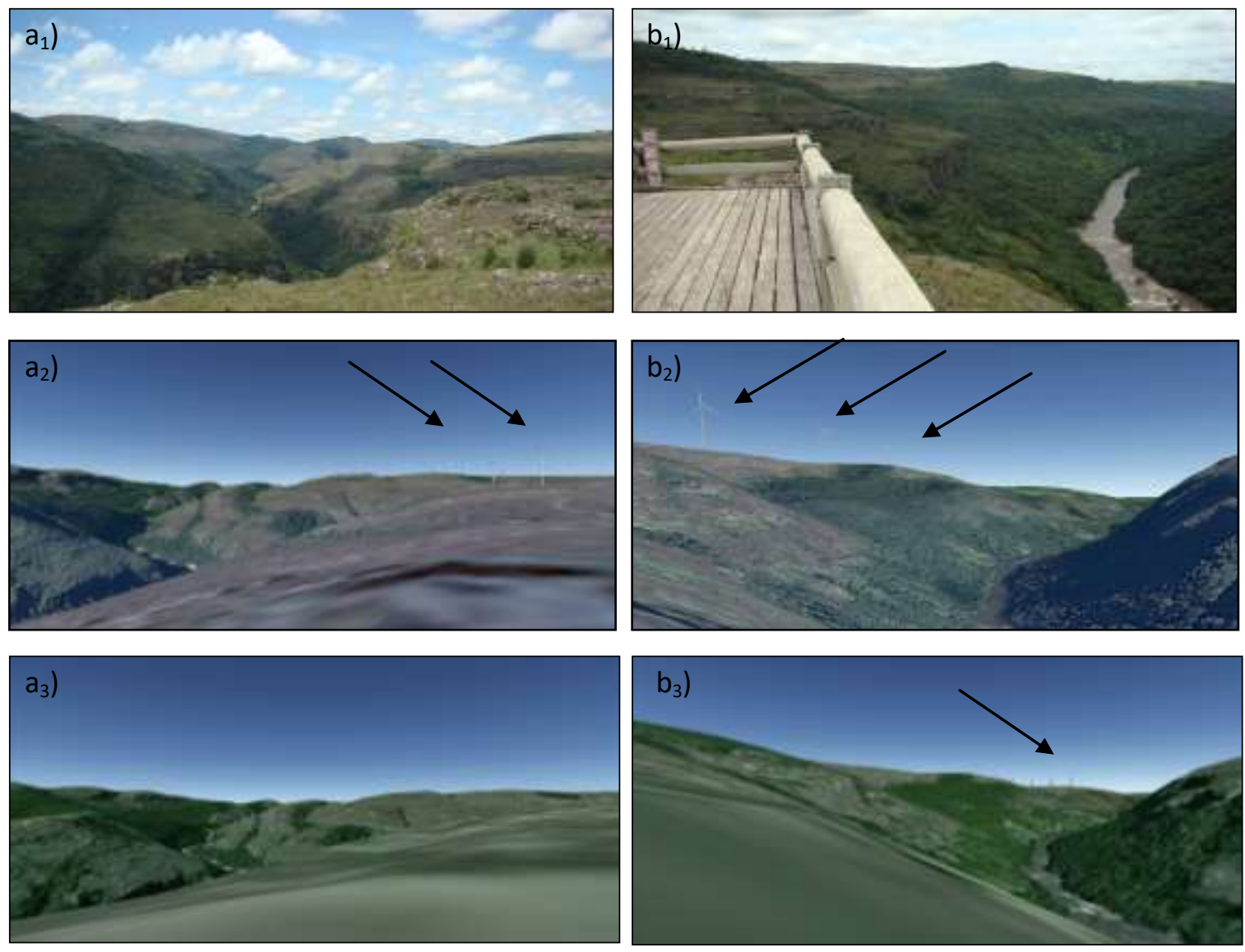

Figura 7: Comparativo da situação atual $\left(x_{1}\right)$ com simulação da implantação do Complexo Eólico Campos Gerais AL1 $\left(x_{2}\right)$ e AL2 $\left(x_{3}\right)$ a partir do (a) PV3 (sentido oeste em direção ao canyon do rio lapó) e (b) PV4 (vista para jusante do rio lapó). 
Considerando a chave de interpretação para avaliação do grau de impacto visual das turbinas a partir dos pontos de contemplação da paisagem no Parque Estadual do Guartelá tem-se que, no projeto da AL2, os pontos de visada simulados não terão impactos negativos significativos no que tange os aspectos de qualidade visual e estético da paisagem.

Em todos os pontos simulados é possível o observador notar a presença do CECG, entretanto pela distância média entre o observador e os aerogeradores, estima-se que estes serão incorporados a visualização plena da paisagem devido a sua não representatividade em termos de tamanho e forma com relação a paisagem de entorno.

Em geral, o relevo local é caracterizado por extensas mesetas planas, com topos suavemente ondulados, cortados por vales estreitos e profundos gerando escarpas fortemente inclinadas terminadas em depósitos de talus e cortadas por vales estreitos. Desta maneira, a implantação dos aerogeradores prevê o aproveitamento das áreas com as maiores cotas altimétricas na paisagem. Assim, o contraste entre as turbinas geradoras de energia e a paisagem visualizada a partir destes pontos de observação é minimizado, uma vez que o relevo em torno do canyon do rio lapó faz com que os aerogeradores sejam implantados em cotas diferentes.
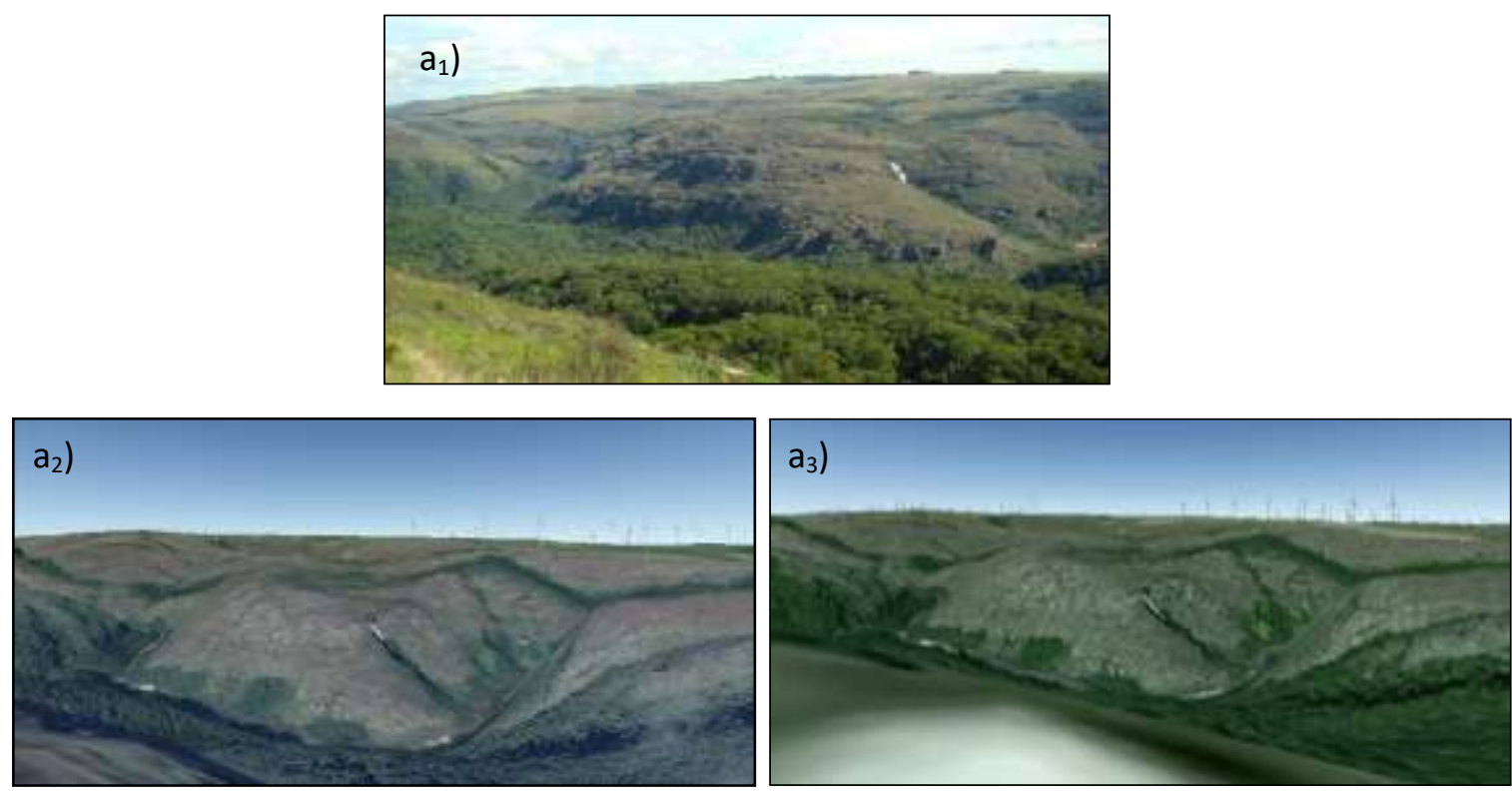

R. Ra'e Ga - Curitiba, v. 38, p. 221-244 , Dez/2016 
Figura 8: Comparativo da situação atual $\left(x_{1}\right)$ com simulação da implantação do Complexo Eólico Campos Gerais AL1 $\left(x_{2}\right)$ e AL2 $\left(x_{3}\right)$ a partir do PV5 - RPPN Ita-y-tyba - vista em direção ao canyon do rio lapó.

\section{CONCLUSÕES}

Considerando a contextualização teórica apresentada e as modelagens realizadas para avaliação da implantação das duas alternativas locacionais para o Complexo Eólico Campos Gerais, conclui-se que em AL2 não foram observados impactos negativos/positivos em relação a qualidade visual e estética da paisagem. Por outro lado, em AL1, nota-se nos PVs simulados que os aerogeradores apresentam-se com proximidade relativa ao observador, em comparação a AL2, de forma que se estima que o impacto visual associado será superior ao comparado com AL2.

Desta forma, as características morfológicas dos locais de visada simulados permitem a visualização do canyon do rio lapó em primeiro plano na paisagem, observando-se que a implantação dos aerogeradores em AL2 não o tornariam elementos proeminentes na paisagem devido a sua distância em relação ao observador e ângulo de visada dos PV utilizados. Apesar de ambos os projetos de implantação do CECG adicionarem um elemento novo a estética da paisagem, a paisagem de interesse do espectador não será diretamente impactada na AL2.

Em geral, para a AL2 pode-se afirmar que, apesar da presença de aerogeradores inseridos nas áreas de grau de impacto visual Médio a Alto, o Complexo Eólico Campos Gerais não impactará de forma negativa na qualidade visual e estética da paisagem do canyon do rio lapó e do Parque Estadual do Guartelá. Esta constatação é devido aos ângulos de visada nos pontos de interesse turístico do Parque se encontrarem, geralmente, no sentido oposto a implantação do Complexo Eólico Campos Gerais. E quando esta premissa não é seguida, a própria distância entre o observador e os aerogeradores faz com que sua proeminência na paisagem seja relativizada. 
Destaca-se ainda que a percepção da qualidade visual de áreas turísticas está relacionada a suas potencialidades naturais, sendo que estas devem apresentar-se proeminentes na paisagem em relação aos elementos artificiais inseridos posteriormente (i.e. aerogeradores, torres de alta tensão, etc).

Por fim, pode-se fazer uma ligeira aproximação da implantação de um parque eólico ao conceito de resiliência da paisagem ao considerar ainda que o impacto é relativizado por ser temporalmente definido e promover a alteração das formas da paisagem e não de seus processos e funções. Soma-se a esta questão a possibilidade de desmobilização de um parque eólico, retornando as formas originais da paisagem, fato impossível de ser cogitado em outras obras de natureza energética, como por exemplo, a implantação de uma usina hidrelétrica.

\section{REFERÊNCIAS BIBLIOGRÁFICAS}

BISHOP, I.D.; MILLER, D.R. Visual assessment of off-shore wind turbines: the influence of distance, contrast, movement and social variables. Renewable Energy, v. 32, n. 5, p. 814-831, 2007.

BISHOP, I. D. Determination of thresholds of visual impact: the case of wind turbines. Environment and Planning B: Planning and Design, 29(5), 707718, 2002.

BRASIL, República Federativa do. Lei Federal $n^{\circ} 4.771$ de 15 de setembro de 1965, que institui o Código Florestal Brasileiro (substituído pela Lei Federal $n^{\circ}$ 12.651 de 25 de Maio de 2012, que institui o Novo Código Florestal).

BRASIL, República Federativa do. Decreto Federal no 84.017 de 21 de setembro de 1979, que aprova o regulamento dos Parques Nacionais Brasileiros.

BRASIL, República Federativa do. Lei Federal no 9.985, de 18 de julho de 2000, que institui o Sistema Nacional de Unidades de Conservação - SNUC. 
DAITX, J. Impacto na paisagem gerado pelo Parque Eólico de Osório sob a visão dos moradores: análise de resultados e metodologia utilizada. In.: VERDUM, R.; VIEIRA, L.F.S.; PINTO, B.F.; SILVA, L.A.P. Paisagem: leituras, significados e transformações. Porto Alegre: Ed. da UFRGS, 2012. p.87-103.

DANIEL, T.C. Whither scenic beauty? Visual landscape quality assessment in the 21st century. Landscape and Urban Planning, 54(1), 267-281, 2001.

DE VRIES, S., DE GROOT, M., BOERS, J. Eyesores in sight: Quantifying the impact of man-made elements on the scenic beauty of Dutch landscapes. Landscape and Urban Planning, 105(1), 118-127, 2012.

GIPE, P. Design as if people matter: aesthetic guidelines for the Wind Industry, Washington, DC. 1995.

HORNES, K.L. Potencial geomorfológico e geológico para o geoturismo nos parques estaduais do Guartelá, Vila Velha e Cerrado (Paraná, Brasil). Tese (Doutorado em Geografia, Universidade Federal do Paraná), 250p, 2012.

HULL, R. B., BISHOP, I. D. Scenic impacts of electricity transmission towers: The influence of landscape type and observer distance. Journal of Environmental Management, 27(1), 99-108, 1988.

KATSAPRAKAKIS, D. A. A review of the environmental and human impacts from wind parks. A case study for the Prefecture of Lasithi, Crete. Renewable and Sustainable Energy Reviews, 16(5), 2850-2863, 2012.

LADENBURG, J.; DUBGAARD, A. Willingness to pay for reduced visual disamenities from offshore wind farms in Denmark. Energy Policy, v. 35, n. 8, p. 4059-4071, 2007.

LADENBURG, J. Visual impact assessment of offshore wind farms and prior experience. Applied Energy, v. 86, n. 3, p. 380-387, 2009. 
LOTHIAN, A. Landscape and the philosophy of aesthetics: is landscape quality inherent in the landscape or in the eye of the beholder? Landscape and Urban Planning, 44(4), 177-198, 1999.

LOTHIAN, A. Scenic perceptions of the visual effects of wind farms on South Australian landscapes. Geographical Research, 46(2), 196-207, 2008.

MOLNAROVA, K., SKLENICKA, P., STIBOREK, J., SVOBODOVA, K., SALEK, M., BRABEC, E. Visual preferences for wind turbines: Location, numbers and respondent characteristics. Applied Energy, 92, 269-278, 2012.

MOPU. El paisaje. Unidades Temáticas Ambientales de la Dirección General dei Medio Ambiente. Madrid: Min. de Obras Públicas y Urbanismo. 1987. 107 p.

PANIZZA, M.; PIACENTE, S. Geomorfologia Culturale. Bologna, Pitagora Editrice, 2003.

PANIZZA, M.; PIACENTE, S. Geomorphological Assets Evaluation. Zeitschrift fur Geomorphologie, Suppl. 87: 13-18, 1993.

PARANÁ, Estado do. Decreto Estadual no 2.329 de 24 de setembro de 1996, Declara de utilidade pública para fins de desapropriação, o imóvel denominado "Guartelá" localizado no Município de Tibagi/PR.

RETZLAF, J.G.; STIPP, N.A.F.; ARCHELA, E. Breve síntese geológica e geomorfológica da área do Parque Estadual do Guartelá no Estado do Paraná. Geografia (Londrina), v. 15, n. 1, p. 95-106, 2010.

SANTOS, M. A natureza do espaço. São Paulo: Hucitec, v. 1, 1996.

SOARES, O. Canyon do Guartelá, Rio lapó, Paraná. RA'E GA: 0 espaço geográfico em análise, v.1, p.111-117, 1997.

THAYER R.L, FREEMAN C.M. Public perceptions of a wind energy landscape. Landscape and Urban Planning;14: 379-98, 1987. 
AVALIAÇÃO DO IMPACTO VISUAL DE PARQUES EÓLICOS NA QUALIDADE E ESTÉTICA DA PAISAGEM NO ENTORNO DE ÁREAS PROTEGIDAS: ESTUDO DE CASO DO PARQUE ESTADUAL DO GUARTELÁ, PR

UNIVERSITY OF NEWCASTLE. Visual Assessment of Windfarms Best Practice. Scottish Natural Heritage Commissioned Report F01AA303A, 2002.

VERDUM, R.; VIEIRA, L.F.S.; PINTO, B.F.; CABRALES, R. Percepção da paisagem na instalação de aerogeradores no Rio Grane do Sul. In.: VERDUM, R.; VIEIRA, L.F.S.; PINTO, B.F.; SILVA, L.A.P. Paisagem: leituras, significados e transformações. Porto Alegre: Ed. da UFRGS, 2012. p.73-86. 